\title{
LAS ARMAS BIOLÓGICAS. PERSPECTIVAS DE FUTURO
}

\author{
Nieva Machín ${ }^{63}$ \\ UNISCI
}

\begin{abstract}
Resumen:
La valoración de bajo riesgo de sufrir un ataque con armas biológicas realizada por la estrategia nacional de seguridad resulta errónea ya que España como miembro de la OTAN debería recoger en su estrategia nacional de seguridad del año 2013 esta amenaza ya considerada como tal por la OTAN en el año 2002. Para una valoración efectiva del nivel de esta amenaza resulta preciso considerar que esta ha trascendido el ámbito militar. En el presente artículo se presentará la vulnerabilidad de España derivaba de las políticas y protocolos de seguridad de carácter reactivo y no preventivo establecidas en España así como aspectos mutidimensionales que requieren un replanteamiento y mejoras acordes a una valoración de riesgo más precisa.
\end{abstract}

Palabras clave: Armas químicas, riesgo NBQR, Convención sobre Armas Biológicas, proliferación, control, supervisión, prevención, detección, vigilancia, farmacéutica, biotecnológica, Estados parte, GRUPABI,

OPAQ, ingeniería genética, genómica, genoma, agentes biológicos, terrorismo, RELAB.

Title in English: "Biological Weapons: Future Perspectives"

\begin{abstract}
:
The National Security Strategy assesses the risk of suffering an attack with biological weapons as low. This seems to be a clear mistake for the reason that NATO already considered this possibility in 2002. To effectively assess the level of this threat we need to consider that it already goes beyond the strictly military field. In the current article we will show the vulnerability of Spain as derived from policies and security protocols of reactive and not preventive character established, along with multilateral dimensions that require a reconsideration of the real threat, following a more precise evaluation. Important improvements are needed.
\end{abstract}

Keywords: Chemical Weapons, NBQR risk, Convention on Biological Weapons, Proliferation, Control, Supervision, Prevention, Detection, Vigilance, Pharmaceutical, Biotecnological, States Part of, GRUPABI, OPAQ, Genetic Engineering, Genomics, Genome, Biological Agent, Terrorism, RELAB.

Copyright @ UNISCI, 2014.

Las opiniones expresadas en estos artículos son propias de sus autores, y no reflejan necesariamente la opinión de UNISCI. The views expressed in these articles are those of the authors, and do not necessarily reflect the views of UNISCI.

\footnotetext{
${ }^{63}$ Nieva Machín Osés es investigadora junior de UNISCI y miembro del Foro Hispano-Argelino. 


\section{Introducción}

Según lo establecido en la estrategia nacional de seguridad del año 2013 se reconoce como riesgo o amenaza aquellas que tiene su origen en los fenómenos naturales (inundaciones, erupciones volcánicas, ... etc.) así como en el creciente número de catástrofes que tiene su origen en la actividad humana o bien en una combinación de ambos y cuyos efectos pueden causar no solo la pérdida de vidas humanas sino también daños o destrucción de infraestructuras, medios de producción, efectos negativos en los mercados y flujos de abastecimiento además de la aparición o resurgimiento de enfermedades que pudieran afectar a la población o a los animales provocando daños severos en la economía del país. ${ }^{64}$

Si bien lo concerniente a los riesgos y/o amenazas provenientes de fenómenos naturales y nucleares serán tratados en otros capítulos, en el presente capítulo se abordaran los riesgos que provienen del ámbito biológico o químico. Especialmente en lo que atañe a ataques con armas biológicas o químicas.

La consideración de amenaza a los riesgos derivados de acciones/ataques de origen biológico resulta inferior a la que recibe la derivaba de actividad nuclear debido al protagonismo mediático y social que ésta recibe. Así como de la evaluación y la asignación de probabilidades que tiene España de poder sufrir un ataque de dichas características. Según el ministerio de Defensa la posibilidad que tiene España de sufrir un ataque de dichas características es bajo y es asociado principalmente a accidentes, no a actividades terroristas. De hecho las políticas y protocolos de seguridad derivadas de esta planteamiento son principalmente de carácter reactivo y no preventivo. Resulta especialmente llamativo esta consideración ya que países como Francia, Australia, Japón, Finlandia, Estados Unidos consideran no solo la posibilidad de sufrir un atentado bioterrorista como una amenaza real sino una amenaza creciente a nivel nacional e internacional. Los planteamientos de sus estrategias de seguridad no son de tipología reactiva sino también preventiva planteando que los Estados deben en aras de garantizar su propia seguridad y conseguir el equilibrio el ratio amenazas/defensa, proporcionar la dotación a sus fuerzas armadas de sistemas de defensa y armas más eficaces que las de sus potenciales adversarios. Esto requiere de esfuerzos e inversiones en procesos de investigación, aplicabilidad de los resultados de estos y la renovación de material así como de una coordinación de estos esfuerzos de naturaleza científico militar con su aplicabilidad en los sistemas de salud para establecer protocolos de actuación así como de acción de protección y prevención.

La valoración que se da en el plan estratégico de seguridad nacional de "bajo riesgo" a la amenaza y los riesgos derivados de acciones/ataques de origen biológico aparece sustentada en la argumentación estadística de: la utilización en raras ocasiones de las armas biológicas y químicas, así como, en el erróneo bien intencionalismo de la escasa probabilidad de que se dé el uso militar de agentes de esta tipología en un conflicto armado debido a los controles y acuerdos internacionales. Siendo este posicionamiento un gran error que está llevando a España a una situación de vulnerabilidad, ya que como será desarrollado en este artículo, el escenario internacional nos indica que la probabilidad de que este tipo de agentes sean usados con fines militares y/o terroristas es creciente. Debido esto tanto a la mayor disponibilidad y accesibilidad a los conocimientos y tecnologías necesarias para el desarrollo de este tipo de

\footnotetext{
64“"Estrategia de Seguridad Nacional” (2013), pp. 34-35 en http://www.lamoncloa.gob.es/NR/rdonlyres/0BB61AA9-97E5-46DA-A53EDB7F24D5887D/0/Seguridad_1406connavegacionfinalaccesiblebpdf.pdf.
} 
armamento como por la ineficacia de los acuerdos internacionales, sistemas de verificación y control.

El principal acuerdo llegado en esta materia es el llevado a cabo en 1972, la "Convención sobre la prohibición del desarrollo, de la producción y del almacenamiento de armas bacteriológicas (biológicas) y tóxicas y sobre su destrucción”, el cual entró en vigor en 1975, tras la firma de este por 22 países los cuales depositaron los instrumentos de ratificación, entre ellos la antigua Unión Soviética, Reino Unido y Estados Unidos, quienes fueron nombrados depositarios. En esta Convención se prohíbe desarrollar, producir, almacenar o, de otra forma, adquirir o retener agentes microbianos u otros agentes biológicos, o toxinas así como armas, equipos o vectores destinados a utilizar esos agentes o toxinas con fines hostiles o en conflictos armados. Tras más de dos décadas en 1 de enero de 1997, ya eran 140 los Estados que se habían adherido a la Convención, incluidos todos los miembros permanentes del Consejo de Seguridad de las Naciones Unidas. Paradójicamente nos encontramos con que, a pesar de esta gran adhesión, hay países que no lo han firmado, otros que, a pesar de que lo firman, no lo ratifican, otro grupo de países que lo firman con "reservas", otros que se retiran. También habrá ciertos países que lo firmarán y que lo incumplirán sistemáticamente. Esto se debe a la ausencia de una autoridad mundial coercitiva que obligue a los Estados a cumplir con los propósitos de los tratados.

Existe un punto clave en esta convención y es el proceso de negociación que se inició en la década de 1990 para añadir un mecanismo de verificación. En la segunda Conferencia de Examen de los Estados Partes en 1986, los estados miembros acordaron fortalecer el tratado informando anualmente sobre Medidas de Creación de Confianza ante las Naciones Unidas. Paradójicamente en la actualidad, tan sólo la mitad de los firmantes del tratado presentan estos informes anuales de manera voluntaria. En la Conferencia de Revisión de 1991, se estableció un grupo de expertos gubernamentales (conocido como VEREX). Las negociaciones para un protocolo de verificación internacional de carácter vinculante a la Convención sobre armas biológicas tuvieron lugar entre 1995 y 2001 en un foro conocido como el Grupo Ad Hoc ${ }^{65}$.

El borrador de protocolo aprobado en abril de 2001 obligaba a aplicar importantes medidas de control e inspección a las actividades relacionadas con la industria biológica. Esto tenía repercusiones para las empresas del sector, incluidas las de investigación farmacéutica y biotecnológica $^{66}$ y dio lugar a grandes diferencias y divergencias en algunas posiciones de los Estados Partes sobre asuntos claves. El 25 de julio de 2001, el gobierno de Bush, después de realizar una revisión de la política sobre las armas biológicas, decidió que el protocolo propuesto no se ajustaba a los intereses nacionales de los Estados Unidos. En función de las divergencias surgidas, además del anuncio de Estados Unidos sobre su intención de no firmar el acuerdo, ya que según afirmó el representante de Estados Unidos Donald Mahley "A nuestro entender, el borrador del protocolo podría poner en riesgo la seguridad nacional y la información confidencial ${ }^{67 "}$, se tomó la decisión de aplazar la sesión, reanudándose en noviembre de 2002 en Ginebra. Los Estados parte dieron su aprobación a un informe final en

\footnotetext{
65 "An Overview of International Efforts to Prohibit Biological Weapons", Stimson Foundation, en http://www.stimson.org/images/uploads/research-pdfs/Houseofcards_2-background.pdf.

${ }^{66}$ Cervell Hortal, Ma José: "El futuro protocolo de La Convención sobre Armas Biológicas: Repercusiones para el sector industrial", Real Instituto Elcano, $A R I$ n 6 (2003), en http://www.realinstitutoelcano.org/wps/portal/rielcano/contenido?WCM_GLOBAL_CONTEXT=/elcano/elcano es/zonas es/defensa+y+seguridad/ari+6-2003.

67 "EE.UU. rechaza acuerdo de armas", $B B C, 25$ de julio del 2001, en http://news.bbc.co.uk/hi/spanish/news/newsid_1456000/1456270.stm.
} 
el cual fue incluida la decisión de celebrar reuniones de carácter anual, así como reuniones de expertos en los tres años siguientes.

En la Sexta Conferencia de los Estados parte celebrada en Ginebra en Noviembre y Diciembre del 2006, se revisó exhaustivamente la Convención siendo aprobado por consenso un documento final, se determinaron unas medidas concretas y específicas para reforzar la aplicación de la Convención. La posición de los Estados Unidos y en concreto de la administración Bush representada por Mahley en el año 2001 era compartida tanto por la administración Bush, como por la administración Clinton y, como se vería en años posteriores, por la administración Obama, siendo esta última ${ }^{68}$ en el año 2009 quien para asombro de la comunidad internacional rechazó estas medidas reforzadoras de la Convención sobre Armas Biológicas ya que tanto la administración encabezada por el Pentágono, como las industrias farmacéuticas y de biotecnología presentaban una fuerte oposición a los sistemas de verificación por los que se debían permitir la inspección de los laboratorios tanto de propiedad pública como privada, justificando su negativa en la necesidad de protección ante la amenaza terrorista. ${ }^{69}$

La Séptima Conferencia de Examen de la Convención se celebró en Ginebra en 2011. Los resultados de esta fueron insuficientes, ya que no se tomaron decisiones relevantes en las cuestiones fundamentales para reforzar las garantías de cumplimiento ${ }^{70}$. En la Conferencia se acordó dar continuidad al proceso entre sesiones con la finalidad de mantener un mayor dinamismo en el debate sobre el contenido de la Convención. La agenda que se estableció para los siguientes años se había de centrar en: la cooperación y asistencia en el marco del artículo 10 de la Convención, el seguimiento de los avances científicos y tecnológicos, reforzamiento de la aplicación nacional de la Convención mediante las medidas de confianza. 71

Actualmente existe un claro desacuerdo dentro del régimen de la Convención sobre la extensión legítima de los controles y las restricciones a las transferencias de materiales, equipo y tecnología de índole científica entre los Estados Parte. Los países considerados "No Alineados", sostienen que los controles de transferencia con fines de control de armas son injustificados y discriminatorios cuando los beneficiarios están cumpliendo con sus obligaciones para con el régimen de tratados multilaterales pertinentes. En los últimos años, la legitimidad y la utilidad de los controles comerciales estratégicos han sido aceptados en mayor medida, sobre todo en vista de las medidas por las que los Estados están obligados a tomar en base a la Resolución 1540 del Consejo de Seguridad de la ONU. Sin embargo, sigue existiendo una fuerte tensión entre, por un lado, la obligación de promover la transferencia de tecnología entre los Estados Partes con el fin de fomentar la cooperación económica así como el desarrollo y , por otro lado, los requisitos de los controles comerciales estratégicos en los casos en que un Estado Parte considera que otro Estado plantea un riesgo en cuanto a proliferación y , por tanto, no debería tener acceso a los materiales de uso dual, tecnología, equipos o información. En otro orden, a pesar del objetivo general acordado de reducir las restricciones al comercio internacional, otros regímenes jurídicos exigen que los Estados

\footnotetext{
${ }^{68}$ Landler, Mark: "Obama Administration Takes a New Approach to Biological Weapons", The New York Times, 8 diciembre del 2009, en http://www.nytimes.com/2009/12/09/world/09biowar.html.

${ }^{69}$ Tucker, Jonathan B.: "Seeking Biosecurity Without Verification: The New U.S. Strategy on Biothreats". en http://www.armscontrol.org/act/2010 01-02/Tucker.

70 "Seventh Review Conference of the States Parties to the Convention on the Prohibition of the

Development, Production and Stockpiling of Bacteriological (Biological) and Toxin Weapons and on Their Destruction", BWC/CONF.VII. UN, Final Document, Geneva (5-22 Diciembre del 2011).

${ }^{71}$ Hart, John; Trapp, Ralf: "Science, Technology, and the Biological Weapons Convention", en https://www.armscontrol.org/act/2012_10/Science-Technology-and-the-Biological-Weapons-Convention.
} 
impongan controles y mecanismos de supervisión. Las medidas concretas que los Estados toman para asegurar que los esfuerzos de control y supervisión sean eficaces pueden coincidir con las medidas de control adoptadas recogidas en la Convención, fortaleciendo así la percepción de que el requisito para promover la colaboración y el intercambio entre los Estados Parte no se está cumpliendo totalmente.

El interés por desarrollar capacidades en la prevención de agresiones con agentes biológicos se ha incrementado a nivel mundial. En España contamos con el GRUPABI (Grupo de armas biológicas), este grupo vinculado a las OPAQ y que reúne a los organismos implicados en relación al riesgo Biológico y trata la seguridad frente al terrorismo. ${ }^{72} \mathrm{La}$ misión de la Organización para la Prohibición de las Armas Químicas (OPAQ) es la eliminación de todo tipo de armas químicas a nivel mundial. Su ámbito de actuación es la comprobación de la destrucción de todas las armas químicas existentes y velar por su no producción. La OPAQ da asistencia y protección a sus Estados Partes en el caso de sufrir amenazas o ataque con armas químicas y promueve la cooperación internacional para el desarrollo de la química con fines pacíficos ${ }^{73}$.

Sin embargo, a pesar de lo anteriormente expuesto la Convención es un acuerdo no operativo ya que las actividades de investigación y producción de armas de origen biológico gracias a actividades de ingeniería genética no suponen una infracción del tratado ya que se permite la producción controlada de ciertas cantidades de este tipo de armamento cuya finalidad es defensiva. Por tanto dicho acuerdo es ambivalente y no operativo ya que precisamente este es el punto clave a precisar, los matices que llevan a establecer de modo inequívoco la diferenciación entre qué es ofensivo y qué defensivo.

Actualmente se están incorporando técnicas de ingeniería genética a la elaboración de este tipo de armamento aumentando su efectividad y convirtiendo estas armas en una tipología muy atractiva para fines tanto militares como terroristas ya que gracias a este proceso conjunto se da lugar a la elaboración de unas armas altamente destructivas que requieren un breve margen de tiempo para actuar. ${ }^{74}$

En los últimos años los avances en el campo de la ingeniería genética han sido realmente revolucionarios, especialmente los concernientes a la genómica, que diferenciándose de la genética clásica, la cual, a partir de un fenotipo, frecuentemente mutante, busca el o los genes responsables de ese fenotipo. Sin embargo la genómica trata de predecir la función de los genes partiendo de su secuencia o de las interacciones que lleva a cabo con otros genes. ${ }^{75}$

Los estudios genómicos se caracterizan por su interdisciplinaridad debido a que el gran número de datos generados en un estudio de este tipo requiere combinar tanto conocimientos biológicos como estadísticos e informáticos. ${ }^{76}$

Los genomas que han sido secuenciados hasta la fecha están siendo muy útiles para la humanidad, entre ellos se cuenta con el humano cuyo estudio se finalizó en el año 2005,

\footnotetext{
${ }^{72}$ Ministerio de Industria, energía y turismo, Autoridad Nacional para la Prohibición de las Armas Químicas, en http://www.minetur.gob.es/industria/ANPAQ/Paginas/Index.aspx.

${ }^{73}$ Organización para la Prohibición de las Armas Químicas, "Información general", en https://www.opcw.org/sp/.

${ }^{74}$ Van Aken, Jan; Hammond, Edward: "Genetic engineering and biological weapons", European Molecular Biology Organization (EMBO), vol. 4, Suppl. 1 (Junio 2003), pp. S57-S60.

${ }^{75}$ National Human Genome Research Institute, "A Brief Guide to Genomics" (3 de Diciembre de 2011), en www.genome.gov.

${ }^{76}$ Oxford English Dictionary (2008): "Genome n", Oxford, Oxford University Press.
} 
identificándose unos 28.000 genes. La secuenciación de los genomas aporta una información valiosísima sobre todos los procesos que se dan en los organismos vivos, teniendo esto una relevancia para el estudio del comportamiento, evolución, tratamiento de enfermedades y desarrollo de vacunas. Este descubrimiento presenta un doble uso, el destinado a fines terapéuticos como la utilización de estos descubrimientos con fines bélicos. Gracias a las herramientas disponibles actualmente, es posible identificar cuáles son los genes de un patógeno que le hacen resistente a los tratamientos y cuáles por el contrario le confieren mayor grado de virulencia. Esta información junto con el uso de sofisticados instrumentos biotecnológicos que permitan la extracción del $\mathrm{ADN}$ de un microorganismo aquel gen portador de la característica deseada, para su manipulación y posterior introducción en el genoma de otro que contiene otra característica deseada, dando lugar a un nuevo microorganismo que presenta la suma de ambas características y que gracias a ellas es susceptible de ser utilizado como un arma biológica.

Resulta relevante destacar que esta tecnología está posibilitando la creación de un agente cuya actuación pueda ser selectiva ${ }^{77}$, funcionaria con agentes de origen biológico especialmente creados para marcar espacios moleculares específicos de ciertos grupos étnicos y será capaz de reconocer secuencias de ADN halladas dentro de sus células, así como permanecer en Estado de latencia, hasta que se diera cierta circunstancia que propiciara inicio de la sintomatología e inicio clínico de la enfermedad, por ejemplo una variación en la humedad relativa del ambiente, la temperatura o mediante la ingesta de cierto alimento .

Esto plantea la cuestión del seguimiento de los nuevos ADN provenientes de las nuevas formas de vida creadas en laboratorios. Las empresas privadas biotecnológicas y los distribuidores de componentes de ADN deberán de etiquetar todos sus productos. El comercio de las secuencias genómicas debe ser transparente y cuyo etiquetaje permita la trazabilidad, con etiquetas de nucleótidos que provean de la información necesaria para su control y evaluación. La industria del genoma debe autofinanciar el seguimiento y la aplicación necesaria de la normativa así como permitir las inspecciones gubernamentales de libre disposición, en caso de fallos en la bioseguridad o la seguridad del laboratorio ${ }^{78} \mathrm{o}$ incidencia en los planes y/o acciones de bioseguridad nacional e internacional.

Selon Joshua Lederberg ${ }^{79}$, premio Nóbel de Fisiología y Medicina afirmó ya en 1956 que: "los microorganismos son la bomba atómica de los pobres". Haciendo una comparación entre los costes de producción y el alcance que proporcionan la diferente tipología de armamento destaca el bajo coste de las armas químicas y biológicas frente a las nucleares o convencionales ya que la posibilidad de afectar un 1000m 2 tiene un coste de 600 dólares con armas químicas y un dólar con armas biológicas frente a los 2.000 dólares que costaría con armas convencionales y los 800 con armas nucleares. ${ }^{80}$

\footnotetext{
${ }^{77}$ Dando, Malcom R. (2002): "Genomics and the new biotechnology" (capítulo 8), en Preventing biological warfare, Basingstoke, Palgrave Macmillan.

${ }^{78}$ Laurie, Garrett: "Biology's Brave New World. The Promise and Perils of the Synbio Revolution", Foreign Affairs, vol. 92, no 6 (Noviembre/Diciembre 2013), pp. 28-46.

${ }^{79}$ Catedrático de Genética, fue Director del departamento de Genética de la Universidad de Stanford y director de los laboratorios Kennedy de Medicina Molecular. Descubrió la reproducción bacteriana por conjugación, siendo esta un intercambio mutuo de genes entre organismos unicelulares no diferenciados sexualmente. Fue el descubridor de que algunos virus transportan material hereditario de una célula bacteriana a otra alterando la herencia de sus huéspedes.

${ }^{80}$ McGovern, Thomas W., MD, MAJ, MC., George W. Christopher, LTC, USAF, MC.: "Biological Warfare and its cutaneous manifestations", en http://telemedicine.org/biowar/biologic.htm.
} 
El Ex ministro de Defensa israelí Barak en una conferencia celebrada en el Instituto Internacional para Estudios de Seguridad Nacional con sede en Tel Aviv afirmo que "en el futuro vamos a ver el terrorismo respaldado por la ciencia y la tecnología" y que las amenazas de ataques biológicos por parte de actores no estatales también presentan peligros cada vez mayores. Barak advirtió: "en algún lugar en un pequeño laboratorio, elementos hostiles se sientan a planear el futuro de armas de destrucción masiva. Siendo esto un potencial de terrorismo sin precedentes" además añadió que "No podemos esperar hasta que se dio cuenta de la amenaza, ya que la brecha será difícil de cerrar",

Este potencial viene dado por la existencia de cierta similitud bélica entre las armas biológicas recombinadas genéticamente y las nucleares. Ya que ambas poseen un alto poder destructivo, sin embargo las armas biológicas recombinadas genéticamente superarían en efectividad a las nucleares ya que estas no atentarían contra las infraestructuras del país sino que afectarían a la población humana, favoreciendo que el país agresor pudiera ocupar sin mayor obstáculo el área atacada siempre y cuando la población ocupante estuviera vacunada.

Se han clasificado los agentes biológicos en tres categorías en base a su impacto en la población $^{82}$ :

-Categoría A: Agentes de fácil diseminación o que se transmiten persona a persona, causando una alta mortalidad y cuyo impacto en la salud pública es alto Por ejemplo: Virus de la viruela; Bacillus anthracis, (ántrax o carbunco); Yersinia pestis, (peste); la toxina de Clostridium botulinumcausante del botulismo; Francisella tularensis, (tularemia) y otros virus como por ejemplo los filovirus (Ebola y Marburgo) o arenavirus causantes de la fiebre de Lassa o la fiebre hemorrágica argentina (virus Junin).

-Categoría B: Agentes con capacidad moderada para su diseminación e inducción de cuadros mortales precisando métodos especiales para su diagnóstico: Coxeilla burnetti (Fiebre Q), Brucella spp., Burkolderia mallei, enterotoxina B deStaphylococcus, Alfa virus como encefalitis venezolana y encefalitis equina. Agentes susceptibles de diseminación vía hídrica o alimentaria como por ejemplo las bacterias Salmonella, Vibrio cholerae, Shigella dysenterie,Escherichia coli O157:H7 y el parásito Cryptosporidium parvum.

-Categoría C: Agentes que pueden ser modificados o creados mediante ingeniería genética. Por ejemplo: los virus Nipah, Hanta, de la fiebre amarilla y los causantes de encefalitis transmitida por garrapatas, además de cepas de tuberculosis multirresistentes.

En cuanto a las vías de entrada de un organismo en un ser humano o animal pueden ser divididas en tres grandes grupos que son: a través del aparato digestivo, por inhalación y por inoculación o absorción a través de la piel. Por otra parte, las formas por las que se pueden diseminar de los agentes biológicos y toxinas son muy diversas, tantas como podamos imaginar, pero podemos hacer tres grupos principalmente: aerosoles (inhalación y absorción), agentes vectores (inoculación), sabotaje de alimentos y agua potable (ingestión). El método de

\footnotetext{
${ }^{81}$ Lappin, Yaakov: "Barak: Enemies will be able to choose which building to hit within 5 years. Ex-defense minister warns of 'unprecedented' chemical, biological terrorism threat", Jerusalem Post, (27 de marzo de 2014). ${ }^{82}$ Khan AS, Morse S, Lillibridge S.: "Public-health preparedness for biological terrorism in the USA", The Lancet, vol. 356, n 9236 (2000), pp. 1179-11.
} 
diseminación usado estará en función de la vía de entrada del organismo, de las características de los agentes empleados y de los resultados que se pretenden obtener. Además el daño producido en el organismo, en muchos casos, va a depender de la vía de entrada en organismo. Un ejemplo de ello es la mortalidad causada por Ántrax, alcanzando un 5\% si es vía cutánea, un $30 \%$ si es vía digestiva y un $80 \%$ si es vía respiratoria ${ }^{83}$.

Uno de los retos de la sociedad internacional en cuanto a la investigación genética es el derivado del control, vigilancia de los proyectos y su doble uso así como la identificación, localización, y sistemas de seguridad de los laboratorios que realizan investigaciones de esta tipología, ya que pueden suponer un riesgo considerable para los civiles que viven en zonas cercanas a los laboratorios. Considerando también que incluso el proceso de transporte de esta tipología de armamento puede conllevar también riesgos importantes para la población. Pero a este reto se suma la dificultad de precisamente no ya controlar la actividad investigadora de los laboratorios sino la mera localización ya que la proliferación de estos a nivel mundial ha sido alarmante en los últimos 20 años así como la rápida difusión de información y accesibilidad a un conocimiento, a nivel global, susceptible de ser usado para el desarrollo de armamento biológico ${ }^{84}$.

Ante los avances en el ámbito genético, biológico a los que estamos asistiendo en los últimos años, la proliferación de proyectos de investigación vinculados al uso militar de estos y lo anteriormente expuesto cabe replantearse la valoración de un posible ataque biológico como una amenaza real y creciente a la seguridad nacional española, ya que los actores no estatales tales como grupos terroristas u organizaciones criminales tienen la posibilidad de acceder a los agentes biológicos susceptibles de ser usados en sus ataques. Así mismo, el modelo de conflicto asimétrico motiva el auge y la proliferación de esta tipología de armamento ya que países con capacidades armamentísticas convencionales limitadas puedan optar por estas armas como medida tanto de respuesta como disuasoria. ${ }^{85}$

La preocupación relativa a este fenómeno está en aumento y a los tradicionales riesgos y amenazas para la seguridad nacional española ha de considerarse los que provienen del desarrollo, posesión, compra o tráfico de armas de destrucción masiva por parte de grupos terroristas, el crimen organizado y actores estatales.

Cabe destacar como ya en la resolución 321 de la Asamblea de Parlamentarios de la OTAN sobre terrorismo con armamento químico, biológico, radiológico y nuclear la Asamblea de la OTAN reconoce que tras los atentados sufridos en Estados Unidos por ántrax hemos entrado en una nueva y peligrosa era la del uso de armas biológicas con fines terroristas. Manifiesta también la preocupación porque los terroristas, aprovechando las precarias condiciones de seguridad en algunos sitios, podrían adquirir ilegalmente tecnologías de armas provenientes de los programas de la antigua Unión Soviética. Destacan que las medidas eficaces para disuadir y defenderse contra el terrorismo utilizando armas biológicas deben llevarse a cabo a través de un esfuerzo coordinado y multilateral en la medida de lo

\footnotetext{
${ }^{83}$ Maroto Rubio, M.; Rojano, B.; Calvo, E.: "Bioterrorismo", JANO, Servicio de Medicina Interna I. Hospital Clínico Universitario San Carlos (La Medicina Hoy), vol. 64, no 1470. JANO (4-10 abril de 2003), en http://www.jano.es/ficheros/sumarios/1/64/1470/49/1v64n1470a13045754pdf001.pdf.

84 "Chemical and Biological Weapons Status at a Glance", Arms Control, Section: Fact Sheets \& Briefs (5 de febrero de 2014), en https://www.armscontrol.org/factsheets/cbwprolif.

${ }^{85}$ Barnaby, Wendy (2002): Fabricantes de epidemias. El mundo secreto de la guerra biológica, Madrid, Siglo veintiuno de España editores, S.A., 2002.
} 
posible. Establece que para maximizar la eficacia en la reducción del alcance de la amenaza, la respuesta internacional requiere en primer lugar un enfoque transatlántico integrado. ${ }^{86}$

Tras considerar todo lo anteriormente señalado podemos afirmar que la valoración de bajo riesgo realizada por la estrategia nacional de seguridad resulta errónea, ya que España, como miembro de la OTAN, debería recoger en su estrategia nacional de seguridad del año 2013 esta amenaza ya considerada como tal en un foro tan significativo como la Asamblea de Parlamentarios de la OTAN ya en el año 2002. Para una valoración efectiva del nivel de esta amenaza resulta preciso considerar que esta ha trascendido el ámbito militar. Esto se debe al fenómeno de la globalización, la difusión de la información y los avances científicos que han favorecido la accesibilidad a este tipo de armamento por parte de organizaciones criminales y grupos terroristas, siendo este un hecho incuestionable; así como a la persistencia en algunos países de programas biológicos debido a que el control de este tipo de programas resulta complejo ya que el doble uso que se puede realizar de estas investigaciones pude responder a unos fines pacíficos o bélicos, hay que añadir que el control internacional de este tipo armamento no ha tenido resultados satisfactorios dada la complejidad del control sobre sus procesos productivos, su fácil transporte y el bajo coste de producción/mantenimiento de las mismas.

La toma de conciencia no alarmista sobre esta amenaza así como el análisis técnico de la misma posibilita el desarrollo de capacidades preventivas y/o de reacción ante un ataque de origen biológico hacia España o los intereses españoles.

En la resolución 321 se insta a los países miembros a: controlar la transmisión de la información clasificada que podría ser utilizado para las armas biológicas y restringir el acceso a la información genética sobre patógenos peligrosos sin dejar de ser sensible a la legítima investigación científica, médica, o de otro tipo que podrían ser utilizados en las armas de destrucción masiva; tomar medidas nacionales concertadas para fortalecer las regulaciones de bioseguridad y aumentar constantemente la protección física de los agentes biológicos altamente letales; mejorar las defensas de la Alianza contra ataques biológicos, incluida una mejor formación, la mejora de los equipos de protección, así como el desarrollo y la adquisición de sensores de aire móviles para la alerta temprana; establecer un dispositivo de respuestas a los ataques terroristas, que incluyen estrategias de información pública y la preparación y formación de personal médico para reconocer y responder a los agentes no familiares y adaptarse a las nuevas condiciones médicas estando integrado el sistema de salud público a nivel nacional; así como desarrollar acuerdos de asistencia internacional rápida y eficaz para complementar y apoyar las capacidades defensivas nacionales ${ }^{87}$.

En base a esto cabe destacar la directiva de defensa nacional 01/2008 la cual recoge precisamente que a los tradicionales riesgos y amenazas a la seguridad han de incorporarse otros que tienen la capacidad de dificultar y degradar el desarrollo social y económico de un país, conjunto de países o regiones con consecuencias negativas nacionales e internacionales, cobrando especial relevancia el terrorismo, el crimen organizado y la proliferación de armas de destrucción masiva, las cuales, según esta directiva, constituyen el conjunto de amenazas transnacionales más importante para la sociedad española ${ }^{88}$.

\footnotetext{
86 "Resolution 321 on terrorism with chemical, biological, radiological and nuclear weapons", OTAN, Asamblea Parlamentaria (4-10 Abril de 2003), en http://www.nato-pa.int/default.asp?SHORTCUT=284.

87 Ibid.

88“Directiva de defensa nacional 01/2008", Consejo Nacional de Defensa, p. 3, en
} 
Esta consideración es debida principalmente a los ataques terroristas del 11 de septiembre del 2001 en new York, los sufridos en España el 11 de marzo del año 2004 y el llevado a cabo el 7de julio de 2005 en Londres que, junto a otros atentados, dejan patente el incremento en las capacidades y la voluntad de ocasionar graves daños con acciones terroristas. Resulta oportuno destacar la tentativa de atentado en un vuelo de Ámsterdam con destino Detroit en Diciembre del año 2009, que, en el caso de haber tenido éxito, hubiera sido un atentado de gran envergadura por el número de víctimas, grado de letalidad y daños causados directa e indirectamente.

Abundando en este tema también es útil reseñar que, en el año 2006, INTERPOL lanzó la segunda fase de su programa de prevención en bioterrorismo. En ella señaló la carencia del apoyo legislativo a la comunidad responsable de la aplicación de la ley, como uno de los problemas más significativos. En el proyecto de biocriminalización se enfrenta la cuestión en tres áreas: el desarrollo de una completa y minuciosa comprensión de los marcos legales de los países miembros en el área de bioterrorismo; la identificación de fallos o agujeros legislativos y de información; la asistencia a países miembros para redactar legislación. En este contexto, el Ministro de Asuntos Interiores de Ucrania Yuriy Lutsenko declaró que la amenaza del terrorismo bioquímico necesita ser tomada en serio. También el Secretario General de INTERPOL Ronald K. Noble afirmo que "Es necesario tener una legislación efectiva para proveer a la policía de instrumentos para prevenir e investigar amenazas bioterroristas" ${ }^{\$ 9}$. La cuestión es que algunos países cuentan con métodos y organismos encargados de hacer cumplir la ley en materia de bioseguridad que son de vanguardia, sin embargo otros países, por su escasa actividad biológica sintética apenas cuentan con una efectiva regulación. Los funcionarios encargados de hacer cumplir la ley de todo el mundo deben aprender mecanismos de evaluación de futuras amenazas y estar preparados en materia de mitigación ante las consecuencias de un ataque biológico dentro de las fronteras nacionales o bien el que pudiera darse en un país vecino. Afirma también que ha de articularse una estrategia policial a nivel mundial para hacer frente a la biología sintética que realice labores de difusión del conocimiento de las amenazas potenciales, sin por ello obstaculizar las labores científicas. $^{90}$

Actualmente la mayor amenaza que sufre la seguridad nacional española en cuanto a posibles ataques bioterroristas de naturaleza biológica es la que proviene del el terrorismo islamista y en particular por la organización Al Qaeda, sus grupos asociados o células autónomas. Gracias a las investigaciones realizadas por el ministerio de defensa español, fuerzas y cuerpos de seguridad nacionales así como otras instituciones nacionales e internacionales se observa una tendencia a que la actividad terrorista sea realizada por células más pequeñas e incluso personas aisladas cuyo soporte pasa por una adhesión de tipología ideológica que pudiera implicar o no una adscripción operativa a la organización.

http://webcache.googleusercontent.com/search?q=cache:wXS2NqCknMgJ:www.defensa.gob.es/Galerias/politic a/armamento-material/ficheros/DGM-directiva-defensa-nacional-1-2008.pdf+\&cd=3\&hl=es\&ct=clnk\&gl=es.

${ }^{89}$ Informe 40", CICTE, en http://www.oas.org/es/sms/cicte/Boletin/Informe 40 spa.pdf.

90 Noble, Ronald K.: "Keeping Science in the Right Hands Policing the New Biological Frontier", Foreign Affairs, vol 92, nº 6 (Noviembre/Diciembre de 2013), en

http://www.foreignaffairs.com/articles/140157/ronald-k-noble/keeping-science-in-the-right-hands. 
Según la Memoria 2012 de la Fiscalía General del Estado ${ }^{91}$, el Yihadismo considera a España un objetivo a atacar tal y como queda patente en las numerosas y frecuentes referencias que estos terroristas hacen de España, bien en cuanto a una reivindicación territorial en base al antiguo Al Ándalus, bien respecto a la presencia de fuerzas militares españolas en misiones como UNIFIL en Líbano, ISAF y EUPOL en Afganistán, EURONAVFOR en Somalia y la contribución al conflicto de Malí con la formación de fuerzas de la CEDEAO y apoyo logístico. ${ }^{92}$

Estos grupos terroristas con ideologías religiosas están dispuestos a conseguir el mayor número de víctimas civiles, ya que la población es considerada un objetivo principal al que atacar, bien para conseguir su sometimiento mediante la consecución de la conversión a su sistema de creencias o bien por la erradicación de la población como tal, convirtiéndola en el enemigo a erradicar. ${ }^{93}$ Los artefactos explosivos improvisados o IED ha venido siendo el arma utilizada de modo mayoritario por los grupos terroristas ya que estas son armas se caracterizan por su fácil adquisición y manejo; sin embargo la posibilidad de que este tipo de grupos opte por el uso de las armas biológicas o químicas viene determinado por varias razones:

$\checkmark \quad$ Los efectos son de mayor alcance que con el uso de artefactos IED.

$\checkmark \quad$ Incremento en la escalada espiral de la violencia y búsqueda de alcanzar mayor grado de letalidad en los ataques terroristas.

$\checkmark \quad$ Fácil accesibilidad a la información sobre su empleo y fabricación. de víctimas.

Mayor ratio de proporción de daños causados en cuanto a extensión y número

$\checkmark \quad$ Las reducidas dimensiones del artefacto que facilitan tanto la ocultación como el transporte impidiendo su detección.

$\checkmark \quad$ En el caso de agentes biológicos el factor tiempo, desde que el ataque se ha perpetrado hasta su detección puede ser un factor que dificulte la detención del terrorista ya que esto facilita su huida.

A estas razones hay que sumarle que, gracias a la naturaleza de estos ataques, los terroristas pueden optar por esta tipología de armamento si su objetivo es dañar la vida de los ciudadanos o la salud de la población. Estos ataques pueden realizarlos mediante la liberación de agentes biológicos en la cadena alimentaria o el suministro de agua. Teniendo como consecuencia no solo un efecto adverso en la población, sino también en la economía, ya que los costes en que

91 "Memoria 2012 de la Fiscalia General del Estado", en http://www.fiscal.es/Documentos/Memorias-de-laFiscal\%C3\%ADa-General-del-

Estado.html?pagename=PFiscal\%2FPage\%2FFGE memorias\&cid=1242052134611\& charset $=$ UTF8\&selAnio=2012\&txtPalClave=Memoria+de+la+Fiscal\%C3\%ADa+General+del+Estado\&btnBuscar2=Buscar.

92 "España, sometida a amenazas yihadistas por sus compromisos internacionales",

El Economista, 16 de Septiembre 2013, en

http://ecodiario.eleconomista.es/politica/noticias/5145871/09/13/Espana-sometida-a-amenazas-terroristas-porsus-compromisos-internacionales.html.

${ }^{93}$ Jenkins, Brian M. (2006): "The New Age of Terrorism", en Kamien, David G. (ed.) (2006): The

Homeland Security Handbook, Nueva York, McGraw-Hill. 
se incurriría para llevar acabo la descontaminación serían altísimos. Esto podría verse incrementado debido a la transmisibilidad de los agentes causando entre la población un clima de pánico colectivo que agravaría la situación y un objetivo deseado por estos grupos. ${ }^{94}$

Ante esta panorámica de la amenaza de ataques biológicos, resulta imprescindible para el plan estratégico de seguridad nacional el análisis en profundidad de los riesgos, amenazas que atañen a los interés españoles así como el origen, las causas, la esfera motivacional de dichas amenazas, la detección de autores y facilitadores de estas y llevar a cabo acciones con la finalidad de enfrentarlas desde la esfera pública y privada, gracias a actuaciones de las Fuerzas de seguridad del Estado pero también gracias a las contribuciones de científicos e investigadores.

\section{Plan de Acción de la Unión Europea v el caso español}

La Comisión Europea el 24 de junio de 2009 adoptó su comunicación sobre el refuerzo de la seguridad química, biológica, radiológica y nuclear en la Unión Europea: el Plan de Acción NRBQ de la UE, que se había basado en los resultados de un Grupo de Trabajo NRBQ, creado por la Comisión en febrero de 2008, en el que participaron partes interesadas de todos los países de la Unión Europea tanto de carácter público como privado, así como en los resultados de su seminario de clausura, celebrado en Praga (República Checa), en enero de 2009. El objetivo global del conjunto de políticas de referencia era un planteamiento que tenía en cuenta todos los peligros destinados a reducir la amenaza y el daño provocados por los incidentes NRBQ que tengan un origen accidental, natural o intencionado, incluidos los actos terroristas. El Plan de Acción NRBQ de la UE está destinado a reforzar la seguridad NRBQ en la Unión Europea. Su objetivo global es reducir la amenaza y el daño de los incidentes NRBQ de origen accidental, natural e intencionado. El Plan de Acción NRBQ de la UE se basa, en términos generales, en un planteamiento que tiene en cuenta todos los peligros, incluidos los actos terroristas, y que contribuye a la aplicación de la Estrategia de la Unión Europea de Lucha contra el Terrorismo. El Plan de Acción constituye un compromiso político, que puede considerarse un plan de trabajo para llevarse a cabo en los próximos años.

La ejecución de las acciones previstas en el Plan de Acción NRBQ de la UE debe guiarse por los siguientes principios:

$\checkmark \quad$ Si bien es principalmente responsabilidad de cada Estado miembro proteger a su población contra los incidentes NRBQ, las iniciativas adoptadas en el nivel de la UE deben guiarse por el principio de solidaridad de la UE;

$\checkmark \quad$ Considerando que la Unión Europea puede proporcionar valor añadido a los proyectos de toda la UE, y por lo general asegurar un planteamiento coherente y consecuente en materia de cooperación sobre esta cuestión entre los Estados miembros, el papel de apoyo de la Unión Europea en este ámbito debe ser conforme a los principios de subsidiariedad y proporcionalidad, dando preferencia, siempre que sea posible, a soluciones no legislativas;

\footnotetext{
${ }^{94}$ Katz, Rebecca: "Biological Weapons: A National Security Problem that Requires A Public Health Response", Princeton University, Working Paper 2001-04, en https://opr.princeton.edu/papers/opr0104.pdf.
} 
$\checkmark \quad$ Para evitar la duplicación, las medidas nuevas de la UE que se adopten en este ámbito deben ser coherentes con los reglamentos nacionales e internacionales vigentes y basarse en ellos, así como aprovechar los trabajos existente en otras organizaciones internacionales pertinentes;

$\checkmark \quad$ Las políticas establecidas por el Plan de Acción para abordar los riesgos NRBQ deben desarrollarse en estrecha consulta con las autoridades nacionales y, en su caso, consultando con el sector privado, las instituciones académicas y otras partes interesadas;

$\checkmark \quad$ La acción destinada a abordar la amenaza NRBQ debe basarse en evaluaciones de riesgos y de amenazas, así como en evaluaciones de costes y beneficios, para garantizar que las medidas adoptadas sean pertinentes y eficaces;

$\checkmark \quad$ La confidencialidad de determinadas categorías de información debe tenerse debidamente en cuenta durante la fase de ejecución del Plan de Acción NRBQ;

$\checkmark \quad$ La acción destinada a abordar la amenaza NRBQ debe llevarse a cabo dentro del pleno respeto del Derecho Internacional, incluidos los derechos humanos y el principio del Estado de Derecho;

$\checkmark \quad$ La ejecución de las acciones incluidas en el Plan de Acción NRBQ de la UE se financiará mediante programas e instrumentos comunitarios existentes, incluidos los siguientes Programas: "Prevención, preparación y gestión de las consecuencias del terrorismo y de otros riesgos en materia de seguridad" , "Prevención y lucha contra la delincuencia" , así como el Instrumento de Financiación de la Protección Civil y el Séptimo Programa Marco de la Comunidad Europea para acciones de investigación, desarrollo tecnológico y demostración (en particular el tema de la investigación en materia de seguridad). Además, el Programa de salud 2008-2013 de la UE seguirá apoyando las tareas del Comité de Seguridad Sanitaria y las acciones sobre preparación y respuesta a las amenazas NRBQ a la salud pública;

$\checkmark \quad$ Existe una clara diferencia entre las actividades de detección medioambiental y las de diagnóstico humano. Estas diferentes actividades requieren la participación de especialistas con perfiles diferentes.

En España, el Comité Nacional de Planes Civiles de Emergencia, dependiente del Gabinete de Crisis del Gobierno español, puso en marcha nuevos planes de emergencia frente a riesgos nucleares, químicos y bacteriológicos (Protección NBQ-Nuclear, Biológica y Química) ${ }^{95}$ siguiendo la recomendación de la Unión Europea tras suceder los atentados del 11 de septiembre.

En cuanto a la responsabilidad del operativo NBQ, ésta recae exclusivamente sobre el Estado español, el cual estaría en coordinación con las Administraciones Autonómicas y Locales a través de los Centros de Coordinación Operativa Integrados (CECOPI) en las Delegaciones y Subdelegaciones del Gobierno. Para hacer frente a los riesgos NBQR, las

\footnotetext{
${ }^{95}$ González, Miguel: "España aprueba planes de emergencia ante ataques bacteriológicos, químicos y nucleares”, El país, 17 de octubre 2001, en http://elpais.com/diario/2001/10/17/internacional/1003269610_850215.html.
} 
fuerzas armas españolas cuentan con la Unidad Militar de Emergencias, conocida como la UME, una unidad cuya misión es la intervención en cualquier lugar del territorio nacional, cuando lo decida el Presidente del Gobierno o el Ministro en quien delegue, para contribuir a la seguridad de los ciudadanos en los supuestos de grave riesgo, catástrofe, calamidad u otras necesidades públicas ${ }^{96}$. Dicha unidad fue concebida con el fin de llevar a cabo cometidos específicos vinculados con los riesgos y/o /amenazas señalados anteriormente ${ }^{97}$.

\section{Conclusiones y recomendaciones}

Tras el análisis efectuado hasta ahora cabe señalar que el plan estratégico nacional de seguridad español en cuanto a la amenaza de sufrir ataques de origen biológico ha de ser Preventivo-Reactivo debe mejorar en cuanto a los mecanismos de prevención, precisando la necesidad de un análisis que incluya todo el espectro de los riesgos biológicos y de su control $^{98}$ siendo los elementos constitutivos del espectro de los riesgos biológicos: las enfermedades naturales, los brotes epidémicos, los organismos modificados genéticamente, resistencia a antibióticos y medicamentos, los posibles accidentes en laboratorios, los accidentes de laboratorio resultado de la negligencia y el sabotaje intencional, el uso deliberado de agentes biológicos ${ }^{99}$.

Por tanto el plan estratégico nacional de seguridad español debería articularse en base a las siguientes áreas de actuación: ${ }^{100}$

- Preparación y prevención: La detección, el diagnóstico y la mitigación de enfermedades y lesiones causadas por ataques de origen biológico es un proceso complejo que implica a numerosos actores así como diversas actuaciones y actividades. Resultando necesario proporcionar no solo directrices en materia de salud pública sino apoyo y asistencia técnica a los centro de salud pública locales, autonómicos y estatales para la elaboración de planes coordinados de preparación y protocolos de respuesta. Se deberá fomentar y apoyar los proyectos de investigación vinculados al desarrollo de herramientas innovadoras y estrategias cuyo fin sea la prevención y mitigación de enfermedades y/o lesiones causadas por agentes biológicos .

- Detección y vigilancia: La detección y las actividades de vigilancia resultan imprescindibles para proporcionar una respuesta oportuna. Si la casuística proporciona elementos que faciliten su detección y determinación de su origen biológico la actuación de los cuerpos y fuerzas de seguridad será inmediata, siendo competencia de la policía nacional especialista TEDAX-NRBQ el ámbito urbano y el especialista TEDAX-NRBQ de la Guardia Civil si se da en el medio rural. En el supuesto de que se

\footnotetext{
${ }^{96}$ Unidad Militar de Emergencias (UME), "Concepto de la UME" (2003), p.4, en http://www.defensa.gob.es/ume/Galerias/dossier/Descargas/Dossier_UME_Octubre_2011.pdf. ${ }_{97}$ Ibid., p. 9.

98 Stroot Philippe; Jenal, Ursula: "A New Approach: Contributing to BWC Compliance Via Biosafety, Biosecurity and Biorisk Management", Non Proliferation Review, vol. 18, no 3 (Noviembre 2010), pp. 545-555.

${ }^{99}$ De Salazar Serantes, Gonzalo: "La VII Conferencia de examén de la convención de armas Bacteriológicas y toxínicas: Balance y perspectivas", Instituto Español de Estudios Estratégicos (IEEE) (15 de diciembre del 2013), en http://www.ieee.es/Galerias/fichero/docs_opinion/2012/DIEEEO15-2012_VIIConf_GSal.pdf.

100 "Biological and Chemical Terrorism: Strategic Plan for Preparedness and Response", Center for Disease Control and Prevention, Recommendations of the CDC Strategic Planning Workgroup, MMWR, vol. 49, n ${ }^{\circ}$ RR-4 (2000), en http://www.cdc.gov/mmwr/preview/mmwrhtml/rr4904a1.htm.
} 
trate de un ataque no detectado, con una sustancia infecciosa con posibilidades para producir efectos retardados, con posibles brotes de enfermedad, habrá que apelar también a los servicios de salud, incluyendo médicos, DUE y otro personal sanitario. En cambio, un ataque biológico revestirá las características de un brote de enfermedad, lo que requerirá la implicación decidida de las autoridades sanitarias nacionales, regionales o comunitarias y locales. Ello nos lleva al siguiente planeamiento: la "necesidad de un sistema eficaz de vigilancia de enfermedades" bien diseñado y preparado que permita su rápida activación en caso de emergencia y que esté en permanente conexión con la Red Global de Respuesta y Alerta ante Brotes de Enfermedad establecida por la Organización Mundial de la Salud (OMS). La detección temprana resulta imprescindible para garantizar una respuesta rápida a un ataque de naturaleza biológica esto también incluye la provisión de medicamentos profilácticos, antídotos químicos, o vacunas. Deben estar integrados y coordinados detección, evaluación e informe de sucesos sospechosos que pudieran representar una amenaza en cuanto a materia de salud pública por estar causados por agentes biológicos. Este requiere que los agentes sanitarios tanto nacionales como autonómicos y locales establezcan alianzas con el personal médico de atención primera y urgencias como parte relevante de los mecanismos de alarma temprana y vigilancia del terrorismo biológico.

\section{- Diagnóstico y caracterización de los agentes biológicos:}

Actualmente España cuenta con la unidad de gestión de la RE-LAB compuesta por ocho laboratorios de microbiología que cuentan con instalaciones de alta seguridad biológica, los cuales están especializados en sanidad humana, animal, ambiental, vegetal y alimentaria. Su misión es la identificación rápida y caracterización de los agentes implicados en las amenazas de origen biológico así como la puesta en marcha de nuevas técnicas que proporciones una rápida actuación así como el optimizar el empleo de las existentes.

El Relab debe apoyar y coordinar los medios científico-técnicos necesarios para la toma de decisiones de la autoridad competente en cada caso, en las situaciones de alerta por agentes biológicos.

Las funciones de esta red son: ${ }^{101}$

$\checkmark \quad$ Mantener una red para intercambio de información y coordinación entre los laboratorios, integrando la identificación de riesgos y la planificación y preparación de respuestas en cada situación.

$\checkmark \quad$ Coordinar la información y la comunicación, derivada de las actuaciones, con las distintas Instituciones que participan en la respuesta.

$\checkmark \quad$ Elaborar protocolos de actuación para la comunicación y coordinación de la respuesta de laboratorio (comunicación de amenazas, toma de muestras y traslado de las mismas, actuación del laboratorio, protocolos específicos de procesamiento de muestras.., etc.).

\footnotetext{
101 "Relab Funciones", Ministerio de Economía y Competitividad, Instituto de Salud San Carlos III, en http://www.isciii.es/ISCIII/es/contenidos/fd-servicios-cientifico-tecnicos/fd-re-lab/funciones-relab.shtml.
} 
Formación en el ámbito de estas funciones.

Esta red forma parte del grupo de trabajo nacional para la implementación del Plan de Acción NRBQ de la Unión Europea, estando este coordinado por el Departamento de Infraestructura y Seguimiento de Situaciones de Crisis (DISSC) de Presidencia del Gobierno.

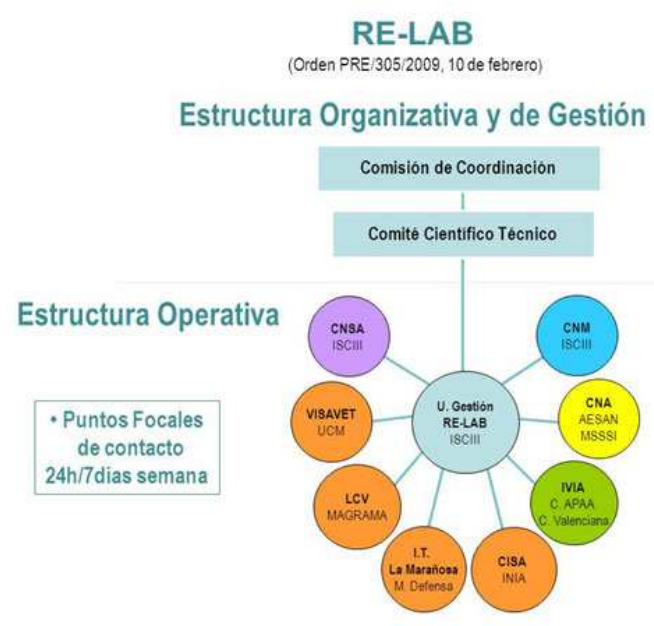

Fuente: Ministerio de economía y competitividad. ${ }^{102}$

Por tanto y debido a la relevancia que supone en este tipo de ataques la detección, se ha de elaborar una red multinivel, que conecte a los laboratorios clínicos, los organismos de salud pública de todas las comunidades autónomas, diputaciones provinciales, municipios y áreas sanitarias. Favoreciendo el intercambio de información, técnicas y resultados de las pruebas realizadas que podrían resultar de interés. Ha de mejorarse por tanto la tecnología de diagnóstico disponible en los laboratorios de los centros de salud y la formación especializada de alguno de los miembros del personal de laboratorio de cada centro. Resulta imprescindible la creación de una unidad de especializada en la confirmación del diagnóstico que en el plazo de 24-48 horas ofrezca una respuesta que posibilite la puesta en marcha de medidas precisas que minimicen el impacto de los agentes en dispersión en el medio ambiente y pueda gestionarse a un nivel más controlado los procesos de descontaminación.

- Respuesta: Se deben establecer unos planes en materia biológica que proporciones una respuesta integral a la salud pública nacional frente a un ataque terrorista biológico consistente en la realización de diversas actividades de investigación epidemiológica, el tratamiento médico y profilaxis de afectados así como la puesta en marcha de medidas de prevención de enfermedades o descontaminación ambiental.

- Sistemas de comunicación: Los sistemas de comunicación resultan clave para mitigar las consecuencias de estos ataques en la salud pública nacional dependiendo el buen funcionamiento de estos de las actividades coordinadas en materia de salud pública, protocolos de actuación y un personal sanitario bien entrenado quienes dispongan de

${ }^{102}$ Ibid. 
acceso a tiempo real de la información necesaria en esta materia de emergencias. La comunicación con la población se realizara a través de los medios de comunicación. Esta comunicación e realizara en materia de profilaxis y de acuerdo con el protocolo de actuación para minimizar el número de víctimas y daños así como evitar tanto el pánico en la población que como hemos señalado anteriormente suele uno de los motivos que promueven la materialización de este tipo de ataques.

Tras todo lo expuesto en el presente artículo, España aparece como vulnerable tanto en el nivel preventivo como en el reactivo, debido a la duplicidad de administraciones en materia de una misma competencia. Esto pone de manifiesto la necesidad de mejorar nuestra capacidad para detectar y controlar los actos de que pudieran suponer un riesgo en materia NBQR y de un modo especial los ataques terroristas de origen religioso cuya naturaleza y motivación hacen incrementar el riesgo de uso de agentes biológicos en sus actuaciones, así como la ausencia de una infraestructura multinivel de comunicación para la salud pública.

Otra vulnerabilidad que presenta España es la existencia de una partida presupuestaria en materia NBQR no acorde con el verdadero y real riesgo que tiene de sufrir un ataque de origen biológico, un plan de actuación no adecuado y actividades de prevención escasas y frecuentemente no coordinadas.

Debido al riesgo creciente de sufrir un ataque de esta índole y según las recomendaciones de la Asamblea de Parlamentarios de la OTAN en la resolución 321, España debe plantearse como una prioridad la revisión integra de esta amenaza tanto a nivel preventivo como reactivo, sus mecanismos nacionales y su papel en los mecanismos internacionales. Teniendo en cuenta que para la gestión del riesgo de ataques de origen biológico resulta necesario: la correcta evaluación de esta amenaza tal y como se ha planteado, impulsar la investigación en materia social y científico técnica, así como las labores de inteligencia en seguridad nacional e internacional que ayuden a detectar fuentes amenazadoras, fomentar programas de formación especializada, realización de ejercicios conjuntos y la difusión de experiencias entre las autoridades públicas, los responsables de la respuesta inicial, investigadores, cuerpos y fuerzas de seguridad del Estado y el resto de la población española. 